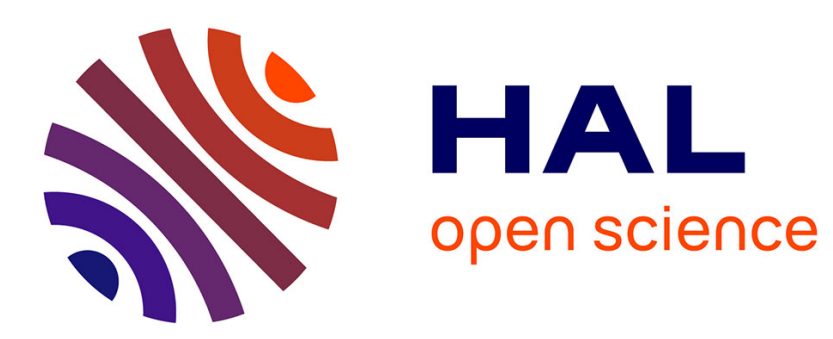

\title{
Combining Ensemble Transform Kalman Filter and FWI for Assessing Uncertainties
}

\author{
Julien Thurin, Romain Brossier, Ludovic Métivier
}

\section{To cite this version:}

Julien Thurin, Romain Brossier, Ludovic Métivier. Combining Ensemble Transform Kalman Filter and FWI for Assessing Uncertainties. 81st EAGE Conference and Exhibition 2019 Workshop Programme, Jun 2019, London, United Kingdom. 10.3997/2214-4609.201901997 . hal-02325633

\section{HAL Id: hal-02325633 \\ https://hal.science/hal-02325633}

Submitted on 24 Nov 2020

HAL is a multi-disciplinary open access archive for the deposit and dissemination of scientific research documents, whether they are published or not. The documents may come from teaching and research institutions in France or abroad, or from public or private research centers.
L'archive ouverte pluridisciplinaire HAL, est destinée au dépôt et à la diffusion de documents scientifiques de niveau recherche, publiés ou non, émanant des établissements d'enseignement et de recherche français ou étrangers, des laboratoires publics ou privés. 


\title{
Combining Ensemble Transform Kalman Filter and FWI for assessing uncertainties
}

\author{
J.Thurin ${ }^{1}$, R. Brossier ${ }^{1}$, L. Métivier ${ }^{2,1}$ \\ ${ }^{1}$ Univ. Grenoble Alpes, ISTerre, F-38000 Grenoble, France \\ ${ }^{2}$ Univ. Grenoble Alpes, CNRS, LJK, F-38000 Grenoble, France
}

February 14, 2019

\begin{abstract}
Full Waveform Inversion (FWI) is an iterative inversion method whose purpose is to retrieve high-resolution models of subsurface physical parameters. Because FWI relies on the solution of a non-linear ill-posed inverse problem, uncertainty estimation is a crucial issue in practical applications, both in seismology and exploration seismic. While uncertainty assessment is a strongly desired feature for FWI, it remains a challenging problem. In this presentation, we investigate uncertainty estimation within the framework provided by ensemble data-assimilation strategies. We combine the Ensemble Transform Kalman Filter and FWI. We review the concepts underlying our ETKF-FWI method, discuss its limitations and appeals for uncertainty estimation, and illustrate it on a 2D multiparameter inversion of an exploration scale field dataset.
\end{abstract}




\begin{abstract}
Full Waveform Inversion (FWI) is an iterative inversion method whose purpose is to retrieve highresolution models of subsurface physical parameters (Virieux and Operto, 2009; Virieux et al., 2017). It relies on the minimization of the misfit between observed and synthetic waveforms computed through wave propagation modeling. The solution of this inverse problem is expected to provide high-resolution estimates of the subsurface parameters, up to half the smallest wavelength of the propagated signal in the diffraction tomography theory. For this reason, FWI has been broadly adopted for exploration geophysics and academic tomography applications from regional to global scale. However, FWI is a non-linear ill-posed inverse problem, and the uncertainty on the numerically estimated solution is high. In particular, it can depend heavily on specific tunings such as initial model design, model parameterization, hyperparameters selection, data-preprocessing.
\end{abstract}

While the ill-posedness of such large scale tomographic problem calls for the evaluation of these uncertainties, the associated computational cost is often a bottleneck for the development of dedicated strategies. Consequently, uncertainty estimation and quality control are in practice mostly limited to data comparison, resolution analysis through checkerboard and point spread function tests, and in-situ comparison with well-log datasets when they are available.

Over the past few years, methodological propositions have shown the potential of a probabilistic framework for uncertainty estimation (Fichtner and van Leeuwen, 2015; Fang et al., 2018). Alongside recent methodological developments, we have proposed the joint application of the Ensemble Transform Kalman Filter (Kalman, 1960; Bishop et al., 2001) and FWI (ETKF-FWI), that have shown potential for uncertainty estimation in a Bayesian formalism (Thurin et al., 2017). This methodology is based on the combination of ensemble data assimilation and classical adjoint-based FWI. The estimation of uncertainty attached to the results is made possible through a low-rank approximation of the posterior covariance matrix. The ETKF formulation allows to include data-uncertainty in the inversion process, which in turns affect both the inversion output and its associated uncertainty estimate.

The ETKF-FWI scheme (Fig. 1) relies on an ensemble representation of the state of the system and its associated uncertainty. Such ensemble representation of the solution is the result by itself, as it gives valuable insights on the mean model and its uncertainty. The ETKF-FWI is carried through two steps. The forecast step (in blue, Fig. 1) consists in applying adjoint-based FWI individually on each model of the ensemble. The analysis step (in red, Fig. 1) is a data-fitting minimization process that takes into account the observed data uncertainty (in green, Fig. 1) and the ensemble repartition altogether. The ETKF-FWI can thus be viewed as a cycle through model-based parallel inversions followed by an ensemble-wise inversion step.

Given an initial mean model, the mean output model of the ETKF-FWI scheme resembles a classical FWI result and corresponds to the parameter estimate. The uncertainty information is embedded in the ensemble repartition and can be extracted from the diagonal and lines of the low-rank version of the estimated posterior covariance matrix. The diagonal of the covariance matrix (the variance) provides information on the diversity of solution for each parameter, which reflects the quality of convergence. The off-diagonal terms allow computing the correlation maps for each parameter, which are a way to evaluate local resolution and the trade-off between parameters.

In this presentation, we will review the ETKF-FWI technique, and illustrate its efficiency on a 2D ocean bottom cable field-data. Results obtained for this applications are shown in Figures 2 and 3, on which we can see the initial and final mean (Fig. 2), as well as variance and correlation maps (Fig. 3). We will also discuss the assumptions and hypothesis underlying the ETKF-FWI scheme, along with the added values of uncertainty estimation in the context of multiparameter inversion, and the feasibility of this approach for its application to 3D field data. 


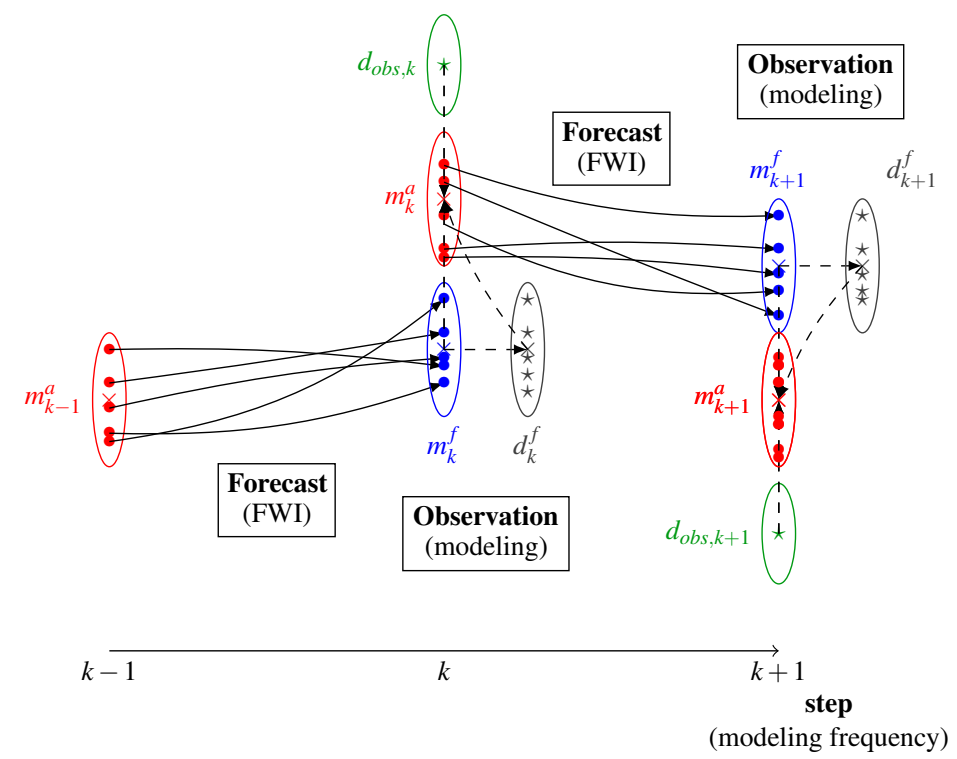

Figure 1 ETKF-FWI scheme. Dots represent velocity models, stars represent wavefield data, crosses and ellipses are respectively means and covariances. Blue denotes the forecast system state, red the analysis, green the observed data and gray the forecast data.
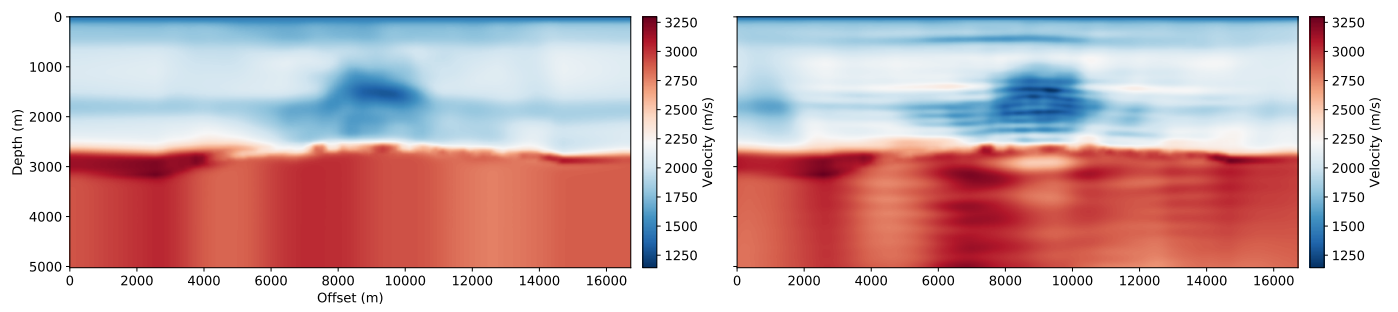

Figure 2 Left: Initial mean model. Right: Final mean model after 6 ETKF-FWI cycles.
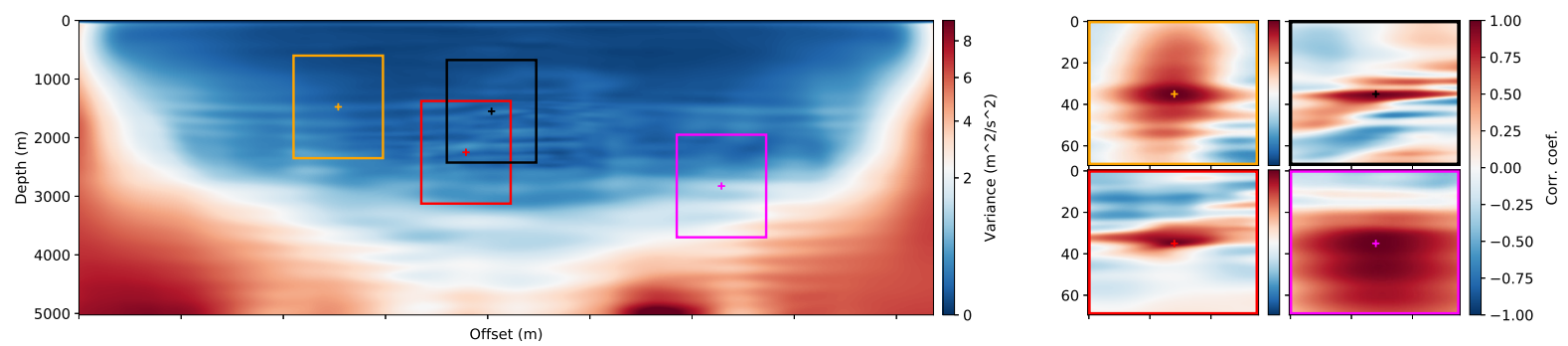

Figure 3 Left: Final variance map obtained from the diagonal of the low-rank covariance matrix. Right: Local correlation maps for four different state parameters obtained from lines of the low-rank covariance matrix.

\section{Acknowledgements}

This study was partially funded by the SEISCOPE consortium (http://seiscope2.osug.fr), sponsored by AKERBP, CGG, CHEVRON, EQUINOR, EXXON-MOBIL, JGI, PETROBRAS, SCHLUMBERGER, SHELL, SINOPEC and TOTAL. This study was granted access to the HPC resources of CIMENT infrastructure (https://ciment.ujf-grenoble.fr) and CINES/IDRIS/TGCC under the allocation 046091 made by GENCI. We thank AKERBP ASA and their partner Pandion Energy for providing the dataset and permission to present this work, and the help of Ross Milne from AKERBP. 


\section{References}

Bishop, C.H., Etherton, B.J. and Majumdar, S.J. [2001] Adaptive sampling with the ensemble transform Kalman filter. Part I: Theoretical aspects. Monthly weather review, 129(3), 420-436.

Fang, Z., Silva, C.D., Kuske, R. and Herrmann, F.J. [2018] Uncertainty quantification for inverse problems with weak partial-differential-equation constraints. Geophysics, 83(6), R629-R647.

Fichtner, A. and van Leeuwen, T. [2015] Resolution analysis by random probing. Journal of Geophysical Research: Solid Earth, n/a-n/a. 2015JB012106.

Kalman, R. [1960] A new approach to linear filtering and prediction problems. Journal of basic Engineering, 82(1), 35-45.

Thurin, J., Brossier, R. and Métivier, L. [2017] An Ensemble-Transform Kalman Filter - Full Waveform Inversion scheme for Uncertainty estimation. In: 87th SEG Conference and Exhibition 2017, Houston.

Virieux, J., Asnaashari, A., Brossier, R., Métivier, L., Ribodetti, A. and Zhou, W. [2017] An introduction to Full Waveform Inversion. In: Grechka, V. and Wapenaar, K. (Eds.) Encyclopedia of Exploration Geophysics, Society of Exploration Geophysics, R1-1-R1-40.

Virieux, J. and Operto, S. [2009] An overview of full waveform inversion in exploration geophysics. Geophysics, 74(6), WCC1-WCC26. 